\title{
Conselhos privados e medicalização da atividade física em um aplicativo de saúde móvel: a produção de corpos homogêneos e sujeitos universais
}

\section{RESUMO}

O "Movimento 21 dias por uma vida mais saudável" (M21) é um programa de educação em saúde que realiza suas ações através de duas plataformas digitais, um site e um aplicativo, para disseminar dicas sobre alimentação, atividade física e convívio familiar. O objetivo do presente artigo é analisar as informações e os conteúdos presentes nas plataformas do M21 sobre o tema atividade física. As análises dos materiais lidos apontam as seguintes questões: o M21 reproduz a lógica medicalizante da atividade física, utilizando-se das formações discursivas próprias do campo biomédico para situála e incentivar a sua prática. A partir de tal enfoque, o programa passa a difundir seus conselhos privados, responsabilizando os indivíduos pela adesão à prática de atividades físicas, desconsiderando, assim, uma série de elementos estruturais que fazem parte da vida da população.

PALAVRAS-CHAVE: Atividade física; Educação em saúde; Medicalização; Saúde móvel
Leonardo Trápaga Abib

Doutor em Educação Física

Universidade Federal do Espírito Santo - UFES

Centro de Educação Física e Desportos

Vitória, Espírito Santo, Brasil leoabib@gmail.com

(Dttps://orcid.org/0000-0001-9335-2141

Ivan Marcelo Gomes

Doutor em Ciências Humanas

Universidade Federal do Espírito Santo - UFES

Centro de Educação Física e Desportos

Vitória, Espírito Santo, Brasil

ivanmgomes@hotmail.com

드 http://orcid.org/0000-0002-0311-9651

Eduardo Lautaro Galak

Doutor em Ciências Sociais

Universidad Nacional de La Plata - UNLP Instituto de Investigaciones en Humanidades y

Ciencias Sociales

La Plata, Argentina

eduardogalak@gmail.com

https://orcid.org/0000-0002-0684-121X 


\begin{abstract}
The "21 Days of a Healthier Life Movement" (M21) is a health education program that carries out its actions through two digital platforms, a website and an application. The idea is to disseminate tips on eating, physical activity and family life. The objective of this article is to analyze the images and discourses at the M21 platforms on the subject of physical activity. The analysis of materials read out the following questions: M21 reproduces the medicalising logic of physical activity, using the discursive formations of the biomedical field to situate it and encourage its practice. From this perspective, the program began to disseminate its private councils, making individuals responsible for adherence to physical activities, thus disregarding a series of structural elements that are part of the life of the population.
\end{abstract}

KEYWORDS: Physical activity; Health education; Medicalization; Mobile health

\title{
Consejos privados y medicalización de la actividad física en una aplicación de salud móvil: la producción de cuerpos homogéneos y sujetos universales
}

\section{RESUMEN}

El "Movimiento 21 días por una vida más saludable" (M21) es un programa de salud pública que realiza sus acciones a través de dos plataformas digitales, un sitio web y una aplicación, para diseminar consejos sobre alimentación, actividad física y convivencia familiar. El objetivo del presente artículo es analizar las informaciones y los contenidos presentes en las plataformas del M21 sobre la actividad física. Los análisis de los materiales apuntan a las siguientes cuestiones: el M21 reproduce la lógica medicalizante de la actividad física, utilizando las formaciones discursivas propias del campo biomédico para situarla e incentivar prácticas "saludables". A partir de tal enfoque, el programa pasa a difundir sus consejos privados, responsabilizando a los individuos por la adhesión a la práctica de actividades físicas, desconsiderando así una serie de elementos estructurales que forman parte de la vida de la población.

PALABRAS-CLAVE: Actividad física; Educación en salud; Medicalización; Salud asistida por móvil 


\section{CONSIDERAÇÕES INICIAIS}

A preocupação com os estilos de vida saudáveis tem sido uma temática recorrente no campo das políticas públicas de saúde desde o advento, durante os anos 1970, da concepção moderna de promoção da saúde, na qual questões ambientais, biológicas, assistenciais e individuais (estilo de vida) passam a ser integradas e relacionadas às noções de saúde-doença (BUSS, 2000).

Desde então, um dos principais efeitos decorrentes dessa concepção moderna de promoção da saúde tem sido a ênfase das discussões ligadas à temática dos estilos de vida da população. Nas últimas décadas vem-se assistindo a uma disseminação cada vez maior de programas e campanhas de educação em saúde que, em grande parte, tem apresentado um enfoque de cunho comportamentalista, priorizando ações de incentivo às mudanças de hábitos cotidianos referentes à alimentação e atividades físicas, em detrimento de ações ligadas às políticas assistenciais e de urbanização (CASTIEL; MORAES; PAULA, 2016; COELHO; VERDI, 2015; NETO et al., 2009; BUSS; CARVALHO, 2009; FERREIRA; NAJAR, 2005; GASTALDO, 1997).

Com o advento das novas tecnologias da informação, da expansão do acesso à internet e do aumento do consumo de dispositivos móveis, como celulares e tablet's, essas campanhas e programas de educação em saúde, focalizadas na prevenção a partir de ações individuais, adentram também em novos campos, como, por exemplo, os da eHealth (saúde eletrônica) e da mHealth (saúde móvel). A saúde móvel, foco deste artigo, consiste no uso de tecnologias de computação e comunicação móveis, como telefones celulares, sensores e outros equipamentos vestíveis, para cuidados pessoais de saúde, para uso de instituições privadas e para programas e ações de saúde pública (WHO, 2011).

Os principais exemplos de serviços de saúde móvel são os sites e aplicativos para serem usados em dispositivos móveis. Estima-se que já existem mais de 165 mil aplicativos voltados para a área da saúde (MATRAVOLGYI, 2016) sendo utilizados por diferentes sujeitos e instituições e para variadas finalidades, tais como coletar dados de índices biológicos (como glicemia, pressão arterial, entre outros), comportamentais (sono, nível de stress, alimentação saudável e atividade física) e ambientais.

Os aplicativos também têm sido utilizados para profissionais da saúde monitorarem pacientes (e para os próprios pacientes se auto monitorar), avaliarem exames e realizarem diagnósticos. Ainda, outras finalidades comuns entre os dispositivos de saúde móvel são as de produzir e promover campanhas de prevenção e educação em saúde que tem como objetivo versar sobre as escolhas de vida das pessoas e a partir disso fornecer conselhos e orientações para 
incentivá-las a escolherem hábitos de vida considerados saudáveis (parar de fumar, alimentar-se de forma balanceada e praticar atividades físicas rotineiramente) (BARRA et al., 2017; ROCHA et al., 2016; LUPTON, 2012).

Utilizando uma linguagem baumaniana podemos dizer que com a ascensão dessas novas tecnologias, a figura dos conselheiros $\operatorname{modernos}^{1}$ expanda-se para novos horizontes, ampliando seu alcance, sem estar restrita ou fixa a um ente centralizador e vertical (BAUMAN, 2001). Dito isso, percebe-se que a temática dos estilos de vida segue atual e que os novos conselheiros da vida saudável (GOMES, 2008) acabam encontrando na saúde móvel mais um campo para controlar, educar, produzir e governar sujeitos.

Seja como uma questão social, moral ou de seguridade, a ideologia da saúde, como apontam Palma et al. (2012), tem ultrapassado os muros das instituições de saúde, passando, assim, a ocupar espaços nas mídias de massa mais relevantes do país, como jornais, revistas, internet, televisão. Nesse sentido, como argumenta Vaz (2003, p. 7), é importante pensar a educação do corpo no mundo contemporâneo em um sentido mais amplo, afinal o corpo é “[...] educado nas escolas, nas igrejas, nos hospitais, nos hospícios, e em muitas outras instituições fechadas, mas também nas ruas, nas tevês, nas revistas ilustradas, enfim, em todos os lugares e tempos que requerem a sua presença”. Seguindo o argumento do autor, acreditamos que a saúde móvel possa estar se constituindo em mais um desses espaços que tem produzido, a partir de seus conselhos privados (BAUMAN, 2001), subjetividades e pedagogias do corpo na atualidade.

Para investigar essas questões referentes aos dispositivos de saúde móvel, optamos por analisar um programa em específico, o "Movimento 21 dias por uma vida mais saudável” (M21), vinculado à Secretaria de Estado da Saúde do Espírito Santo (SESA), e que tem como objetivo o fornecimento de informações, conselhos e desafios nos seguintes eixos: convívio familiar, alimentação saudável e atividade física². Para este artigo temos como objetivo analisar as informações e os conteúdos presentes nas plataformas digitais do M21 referentes a atividade física,

\footnotetext{
1"Hoje o indivíduo tem à disposição uma série de conselheiros, mas não lhe parece mais que haja garantia de verdades duradouras - que, de fato, nunca existiram a não ser no plano das políticas da consciência. Os conselheiros estão espalhados nas diversas prateleiras do mercado, nas instituições governamentais e nos inúmeros outros sistemas de especialistas [...] Uma das características dos conselheiros atuais é que suas ações restringem-se, no que se refere aos resultados, ao mundo privado" (PICH; GOMES; VAZ, 2007, p. 199-200).

${ }^{2} \mathrm{~A}$ opção pelo programa M21 como objeto de estudo deu-se também pelo fato de estarmos como participantes do projeto de pesquisa "A educação do corpo e em saúde nos projetos, práticas e narrativas identitárias na região metropolitana de Vitória/ES”, que tem como proposta analisar a configuração do ideal do indivíduo saudável contemporâneo, tendo por objetivo apresentar uma visão panorâmica da formação do indivíduo saudável no Estado do Espírito Santo. Em um espectro mais amplo, esta pesquisa também faz parte do projeto de cooperação internacional "Sentidos sobre educação do corpo no Brasil e na Argentina: artefatos culturais e biopolítica", projeto entre os grupos de pesquisa LESEF e o CICES/UNLP (Centro Interdisciplinario Cuerpo, Educación, Sociedad da Universidad Nacional de La Plata). O projeto tem como objetivo geral fazer um estudo social do corpo e sua educação através de análises de diferentes artefatos midiáticos, práticas culturais e técnicas corporais que são produzidos e difundidos no Brasil e na Argentina.
} 
buscando identificar e analisar os modos como o programa lida com o tema da atividade física e quais são as possíveis implicações e efeitos que possam decorrer dessas formas. Na próxima seção deste texto apresentaremos o programa M21 e descreveremos as estratégias utilizadas para a realização desta pesquisa.

\section{O MOVIMENTO 21 DIAS POR UMA VIDA MAIS SAUDÁVEL}

No ano de 2015 o governo do Estado do Espírito Santo, por meio da Secretaria de Estado da Saúde (SESA), lançou o Programa Vida Saudável, cujo objetivo central é incentivar a população a realizar mudanças em seu estilo de vida, visando a diminuição dos riscos e agravos em saúde, assim como estimular a prevenção de doenças como diabetes, hipertensão, obesidade e problemas cardíacos. Como parte das estratégias do Programa Vida Saudável, o governo estadual criou no mesmo ano o "Movimento 21 Dias por uma Vida mais Saudável”, um programa de educação em saúde que oferece conselhos, desafios e dicas sobre saúde para a população através de um site e um aplicativo para dispositivos móveis.

Com o intuito de incentivar os sujeitos a iniciarem uma série de mudanças de hábitos, o site e o aplicativo apresentam três eixos de desafios: alimentação saudável, atividades físicas e convívio familiar. Como consta no site, cada grupo tem doze diferentes desafios, dos quais o usuário cadastrado (de forma gratuita) no programa pode escolher um ou mais desses para tentar seguir por 21 dias seguidos. No site e no aplicativo há links para fazer download de peças gráficas ${ }^{3}$, ler notícias e ver vídeos sobre o andamento do M21, conferir o ranking dos usuários cadastrados e obter mais informações sobre temas relacionados à saúde.

Ao abrir o link "Os Desafios" as pessoas têm acesso aos três grupos. Clicando em qualquer um deles, logo aparecerão os desafios do grupo selecionado. Ao selecionar um desafio, o usuário conta com uma descrição e algumas dicas para que possa iniciar a devida prática. Ao aderir a esse desafio, as plataformas digitais do programa passam a acompanhar o processo de cada sujeito, que precisa marcar via site ou aplicativo se conseguiu cumprir com a tarefa escolhida. No aplicativo há um alarme que funciona como um lembrete, onde o programa envia uma mensagem diária perguntando se a pessoa já realizou o seu desafio no dia. A cada dia que o usuário confirma que realizou a atividade escolhida, ele ganha medalhas virtuais, como uma recompensa e um estímulo para seguir em diante. Quando o sujeito conclui os 21 dias ele recebe um troféu virtual. Os troféus e medalhas são contabilizadas e publicadas no link "Ranking"4 dos usuários.

\footnotetext{
${ }^{3}$ Nas plataformas digitais sugere-se que as pessoas façam os downloads dessas peças gráficas para deixarem disponíveis em seus locais de trabalho e moradia no intuito de incentivar mais colegas, vizinhos e familiares a aderirem aos desafios do Movimento 21 Dias.
} 
As atividades propostas pelo M21 são bastante variadas. Por exemplo, no grupo da alimentação saudável constam desafios como diminuir açúcar ou o sal, consumir mais frutas, legumes e verduras, comer cinco cores diferentes de alimentos ao dia, comer de 3 em 3 horas, entre outros. Já no grupo das atividades físicas entre alguns dos desafios sugeridos estão: fazer pequenas pausas para alongamento durante o dia, pular corda por 20 minutos, andar de bicicleta por 30 minutos, espreguiçar ao levantar e praticar esportes coletivos, caminhar ou correr 30 minutos por dia. Por fim, no grupo do convívio familiar são sugeridos desafios como: reunir a família à mesa nas refeições, brincar ou jogar em família, criar projetos em família e promover ambientes harmoniosos ${ }^{5}$.

Ainda a respeito das plataformas de interação do M21, em seu site aparecem fotos das pessoas que se cadastraram no programa, bem como seus nomes completos, desafios concluídos, medalhas e troféus virtuais ficam expostos na página do ranking. Ao se cadastrar no programa, é necessário ler e aceitar o termo de participação no qual uma das questões é o livre uso de imagens, perfis em redes sociais, nomes para serem usados em campanhas, promoções, divulgação etc. O site do M21 sugere ainda aos participantes do programa que utilizem a hashtag \#Movimento21dias nas redes sociais, como Facebook, Twiter e Instagram, com o objetivo de dar maior visibilidade tanto ao programa quanto ao andamento dos desafios assumidos por eles. O uso e a difusão da hashtag também funciona como uma forma de tentar disseminar mais o programa e seus conteúdos na mídia para que mais pessoas possam se inserir e se cadastrarem nele ${ }^{6}$.

Portanto, para compreender e analisar os conteúdos referentes à atividade física nas plataformas digitais do M21 nos debruçamos sobre os textos, imagens, vídeos, peças gráficas, desafios, o ranking de usuários, as estatísticas e as notícias presentes no seu site e aplicativo durante o período de outubro de 2015 (mês/ano em que foi lançado o programa) a outubro de 2018. A partir do endereço http://www.movimento21dias.com.br/ conseguimos acessar todos os materiais utilizados para esta pesquisa. De modo complementar, realizamos o cadastro e o download do aplicativo do M21 para o dispositivo móvel de um dos pesquisadores, com a intenção de entender o funcionamento do aplicativo e de que maneira ocorreria a interatividade com e entre os usuários.

Os conteúdos e dados suscitados pelas plataformas digitais do M21 foram registrados pelos pesquisadores em diários de navegação, onde continham descrições daquilo que estava presente nas

${ }^{4}$ É possível também acessar o ranking dos desafios (quais foram mais assumidos e quais foram mais cumpridos) e dos municípios que tem mais usuários cadastrados nas plataformas.

${ }^{5}$ Para obter maiores informações a respeito da construção e da escolha dos eixos e desafios do M21, ver Abib (2019).

${ }^{6}$ Para além do site e do aplicativo, entre 2015 e 2017 também foram realizadas atividades para divulgação do programa, ocorrendo palestras em instituições públicas e privadas, distribuição de panfletos, veiculação de propaganda na televisão, colagem de cartazes em outdoors e atividades nos Terminais de ônibus da região da grande Vitória - ES em que as pessoas que circulavam puderam aferir pressão, medir altura, pesar-se, aprender técnicas de alongamento e olharem uma exposição que mostrava a quantidade de açúcar e gordura que existe em certos tipos de alimentos. 
plataformas digitais: quais tipos de informações eram mais privilegiados, quem eram os interlocutores das mensagens e notícias, quais desafios eram mais escolhidos pelos usuários, entre outros elementos.

Ao revisitar os diários de navegação optamos por trazer para o presente artigo a discussão de duas categorias, sendo a primeira delas condizente ao processo de medicalização da atividade física e a segunda ao papel do M21 enquanto mais um conselheiro moderno da vida saudável. No decorrer das discussões pretendemos demonstrar como ambas categorias dialogam e se relacionam entre si, de modo a constituírem o referido programa como um espaço para produção de sujeitos e regulação dos modos de vida das pessoas.

\section{OS PROCESSOS DE MEDICALIZAÇÃO NAS MENSAGENS SOBRE ATIVIDADE FÍSICA}

O termo medicalização surge ao final da década de 1960 para abordar a crescente apropriação dos modos de vida do homem pela medicina. Para Gaudenzi e Ortega (2012, p. 22), os autores que vêm estudando esse conceito têm alertado para a "[...] influência da medicina em campos que até então não lhe pertenciam, criando conflitos acerca do estatuto médico, social, epistêmico ou ontológico de determinadas doenças".

Autores como Ivan Illich e Michel Foucault trouxeram importantes considerações a respeito dos efeitos advindos do processo de medicalização na vida da população. Enquanto o primeiro centra sua crítica nas tecnologias médicas, na perda de autonomia dos sujeitos e no excessivo uso de intervenções médicas, o segundo aborda a medicalização social a partir do surgimento da medicina moderna, argumentando que ela havia se apresentado enquanto uma prática social que transformara o corpo do indivíduo em força de trabalho que deveria ser controlado, governado. Ao atuar sobre o corpo biológico e sobre as subjetividades dos sujeitos, o processo de medicalização emerge como uma das implicações do biopoder (FOUCAULT, 2010). No entanto, como argumenta Conrad (2007), atualmente os processos de medicalização são ações coletivas, ou seja, não são compostas somente pela atuação médica na sociedade, mas também de setores organizados da sociedade civil quando, por exemplo, reivindicam tratamentos ou inclusão por meio de diagnósticos médicos -, diferentes categorias profissionais e instituições ligadas ao mercado, que buscam, por vezes, legitimidade através do reforço de discursos medicalizantes para se promoverem.

$\mathrm{Na}$ contemporaneidade os processos de medicalização têm sido expandidos para outras áreas de intervenção, impulsionados com e pelo incremento das neurociências, da genética, da indústria farmacêutica, das correntes comportamentais na área da saúde e educação, entre outras. Diante de 
tal quadro, a hipótese de alguns autores do campo da educação física é de que na atualidade as práticas corporais e as atividades físicas também entraram no bojo desses processos de medicalização da vida (MANSKE; BARCELOS, 2016; DAMICO; KNUTH, 2014; FRAGA et al, 2009; PALMA, 2009).

Ao tornar comportamentos e condutas cotidianas em objetos passíveis de serem balizados pelo binômio normal/anormal, doente/saudável, a vida ativa tornou-se a oposição ao sedentarismo e a prática de atividades físicas passa a ser legitimada prioritariamente pela sua funcionalidade orgânica, pelo discurso da prevenção de doenças e de combate à vida sedentária. Durante esse processo emergem elementos como: a responsabilização dos sujeitos pela quantidade de atividade física que praticam; a disseminação de discursos moralistas sobre as condutas pessoais; a expansão de mercados em torno do estilo de vida ativo; criação de políticas públicas; propagação de práticas regulatórias, entre outros (FERREIRA; CASTIEL; CARDOSO, 2012; BILIBIO; DAMICO, 2011; FRAGA et al., 2009; PALMA, 2009; FRAGA, 2006; GOMES, 2008).

Ao longo das plataformas digitais do M21 pode-se ver uma série de elementos textuais que apontam para uma direção que coloca a atividade física enquanto uma panaceia, uma prática facilmente apropriada pelo saber médico e uma conotação moral que responsabiliza os indivíduos pela sua adesão. Por mais que as plataformas digitais do programa tentem ampliar esse enfoque, o que ocorre majoritariamente é a generalização e o uso funcionalista em torno da prática de atividades físicas:

As atividades físicas são fundamentais na melhoria e manutenção da saúde, porque aumentam a aptidão física, previnem doenças causadas pela falta de movimento e promovem melhorias psicossociais, diminuindo o estresse, aumentando a autoestima e a consciência corporal. E o melhor: podem ser realizadas praticamente em qualquer ambiente e sem auxílio de nenhum equipamento?

No excerto acima, retirado da descrição do eixo "atividade física", nota-se como a atividade física é mobilizada enquanto algo que por si só seria capaz de promover diferentes melhorias à vida humana (físico, emocional, social). Com isso ela emerge enquanto uma questão do campo médicosanitário, de modo, como argumentam Manske e Barcelos (2016, p. 240), a tornarem as experiências humanas “[...] passíveis de serem consideradas como problemas, desvios ou patologias, e desta forma acabam conformando modos homogeneizantes dos seres humanos localizarem a si e aos outros no mundo". Associada a essa panaceia está a noção de que a atividade física apresentaria um caráter de fácil adesão, podendo, inclusive, ser realizada em qualquer ambiente. A partir dessa primeira mensagem a respeito das atividades físicas podemos ter uma ideia

${ }^{7}$ Disponível em < http://www.movimento21dias.com.br/desafios/>. Acesso em 15 de agosto de 2017. 
do modelo de saúde defendido e propagado pelo programa em suas plataformas digitais, sendo esse voltado para prioritariamente para a prevenção e ações de responsabilização dos sujeitos.

Em relação às análises dos desafios que fazem menção a algum tipo de atividade física, os textos apresentados pelo M21 conseguem mobilizar certa variedade de práticas, que vão desde andar de bicicleta, praticar esportes coletivos, corridas e caminhada, até brincar em família, pular corda, subir escadas e espreguiçar-se. Para que essa variedade de práticas se torne justificável, as mensagens exibidas nas plataformas tentam aliar elementos orgânicos e comportamentais por meio de uma linguagem prescritiva, simples e leve, que tem por foco engajar os sujeitos a mudarem suas condutas:

É mais do que comprovado: a dança é uma excelente maneira para exercitar o corpo com regularidade e prazer. Pode ser individualmente, com seu ou sua parceira, na dança você trabalha dezenas de músculos do corpo e faz isso com animação. Para quem acha que praticar uma atividade física é uma obrigação, a dança é excelente opção.

Brincar juntos fortalece os vínculos e a cumplicidade. Além disso, melhora o desenvolvimento e crescimento de crianças, e ajuda na construção de sua identidade. Essa experiência ajuda a relaxar e amplia a capacidade de compartilhar e criar, o que contribui muito para relacionamentos com outros grupos.

Exercitar o cérebro é tão importante para levar uma vida mais saudável quanto exercitar o corpo. Evita a perda de neurônios, melhora a concentração e memória.

Todo mundo já brincou de pular corda um dia. Além de simples e divertido, essa atividade traz grandes benefícios para o corpo [...] De manhã, de tarde ou de noite: escolha o melhor horário pra você e tire apenas 20 minutinhos por dia para encarar esse desafio. É com você!

Embora haja certa diversificação das possibilidades de atividades físicas entre os desafios talvez como forma de afastar-se de uma noção que vincule a prevenção em saúde apenas aos exercícios aeróbicos ou de musculação - há nesses fragmentos um processo de medicalização dessas práticas. Pular corda, exercitar o cérebro, brincar, dançar (e até mesmo subir e descer escadas) tornam-se, pelos textos do M21, práticas referenciadas pelo seu virtual potencial fisiológico e sua incorporação torna-se justificável pela via médico-sanitária, mostrando como tais processos medicalizantes acabam por tentar abarcar esses diferentes campos da vida cotidiana (DAMICO, 2011).

Outro elemento característico dos processos de medicalização emerge quando, segundo Conrad (2007), os problemas passam a ser definidos nos termos médicos, ou seja, descritos por uma linguagem médica e compreendidos com base na adoção de um registro médico. Em uma das seções do site e do aplicativo do M21 visualizamos a seguinte matéria que ilustra tal elemento: 
O médico Marcello Dalla alerta que uma vida sedentária pode causar diversos problemas de saúde, entre eles insônia e depressão, além de mau humor, males que podem ser evitados com a prática regular de atividade física e outros hábitos saudáveis. Colocar o corpo em movimento também ajuda a prevenir osteoporose, doença que enfraquece os ossos e costuma aparecer a partir dos 40 anos de idade. 'Também já está comprovado que a atividade física pode prevenir dois tipos de câncer, o de intestino e o de mama', enfatiza (...) De acordo com o médico, o efeito do exercício físico no organismo é similar ao dos medicamentos, se realizado de forma regular ${ }^{8}$.

$\mathrm{Na}$ mensagem acima novamente a atividade física aparece equiparada a um remédio para prevenir e/ou tratar diferentes enfermidades. O que difere tal mensagem das demais que estão presentes no site é que nela há o endosso de um especialista, neste caso um médico, que aborda as atividades físicas segundo os termos e linguagem próprios da medicina. Como fora possível identificar nos fragmentos supracitados, muitas das mensagens presentes no site e no aplicativo do M21 insistem em colocar a inatividade física (ou baixa prática de atividade física) enquanto doença individualmente regulada, sendo, portanto, a atividade física o medicamento a ser consumido de maneira simples pelos sujeitos, tudo sem maiores problematizações e questionamentos, seja do ponto de vista científico ${ }^{9}$, político ou social.

Contudo é válido salientar que embora a categoria médica tenha exercido ao longo dos anos um grande papel na educação em saúde e indução das condutas da população (FOUCAULT, 2010; CONRAD, 2007), a medicalização da vida não está restrita a ela, de modo que, “[...] as orientações, prescrições e encaminhamentos que originalmente surgem no campo médico são estendidos a outros campos de saberes e áreas da saúde [...] materializando-se, inclusive, em campos não científicos (MANSKE; BARCELOS, 2016, p. 238), como é o caso do aplicativo e do site do M21, que se caracteriza enquanto mais um conselheiro da vida saudável, como será abordado e discutido na próxima categoria.

\section{CONSELHOS PRIVADOS PARA QUESTÕES PÚBLICAS}

O tipo de abordagem apresentado pelo M21 em suas plataformas digitais acabou nos remetendo para dois tipos de ações: primeiro, a programas como, por exemplo, o Agita São Paulo,

\footnotetext{
${ }^{8}$ Trechos disponíveis em < http://www.movimento21dias.com.br/noticia-exibir/hora-rio-de-vera-o-convida-para-a-pratica-de-atividade-fa-sica/3/>. Acesso em 15 de agosto de 2017.

${ }^{9}$ Para além das publicações científicas que falam sobre os efeitos positivos que a prática de exercícios físicos pode proporcionar para qualidade de vida da população, existem também uma série de estudos científicos que mostram que a simples (e recorrente) aposta em políticas de saúde visando a indução e adoção de hábitos saudáveis não é tão eficaz se não estiver acompanhada de ações intersetoriais (REIS et al., 2016; SALLIS et al., 2016) e do combate às desigualdades sociais (STRINGHINI et al., 2017). A respeito dessa temática, ver mais em Holtermann et al. (2012), Palma et al. (2012), Demarest et al. (2013), Andrade et al. (2015), Collins e Haudenhyse (2015), Rodrigues et al (2017).
} 
nos quais o enfoque é dado nas ações individuais e na disseminação de informações a respeito da prática de atividades físicas (COELHO; VERDI, 2015; BONFIM; COSTA; MONTEIRO, 2011; FRAGA, 2006); segundo, às abordagens dos conselheiros modernos que se fazem presentes em jornais, revistas, blogs e outros espaços midiáticos e acadêmicos (GOMES; VAZ; ASSMANN, 2010). Nesse sentido, sugerimos pensar no M21 como mais um conselheiro da vida saudável, ou ainda como um espaço digital que serve como abrigo para outros conselheiros dessa área. Sobre o papel dos conselheiros contemporâneos, Bauman (2001) atenta para o fato de que esses, sejam midiáticos ou científicos, cuidam para não pisarem fora da área fechada do privado:

Doenças são individuais, assim como a terapia; as preocupações são privadas, assim como os meios de fazer para resolvê-las. Os conselhos que os conselheiros oferecem se referem à política-vida, não à Política, com $\mathrm{P}$ maiúsculo; eles se referem ao que as pessoas aconselhadas podem fazer elas mesmas e para si próprias, cada uma para si - não ao que podem realizar em conjunto para cada uma delas, se unirem forças (BAUMAN, 2001, p. 77).

Acerca desse tipo de conselhos apontados pelo autor, ao lermos os fragmentos sobre atividade física em diferentes domínios do site do M21 (para além das informações presentes nos desafios do grupo "atividade física"), pudemos encontrar alguns trechos que nos dão indícios de como o programa coloca a perspectiva da medicalização em articulação com os conselhos da política-vida em detrimento da Política com P maiúsculo:

Segundo Marcello Dalla, médico de família e comunidade da Secretaria de Estado da Saúde do Espírito Santo, o fator mais importante para prevenção de doenças é a prática de exercícios físicos [...] E para quem reclama de falta de tempo, o médico dá uma dica. 'Pense em saltar um ponto antes do local de trabalho para ir andando, e faça o mesmo depois do expediente ao voltar para casa. Pode ser uma solução', comenta $^{10}$.

A fala - extraída de uma notícia veiculada pelo site do M21 - traduz o ideário do autocuidado e da autorregulação ao posicionar o indivíduo como principal responsável por manter um estilo de vida ativo, nem que seja saltando um ponto antes do local de trabalho. Esse tipo de conselho indica uma maior preocupação com a responsabilidade individual, ou seja, com aquilo que o indivíduo deveria fazer por si mesmo, independente das suas circunstâncias. Esse é um exemplo crasso da política-vida apontada por Bauman. Aqui a atividade física é transferida da ótica do direito para a do dever em nome de uma suposta garantia de um futuro livre de doenças. Nesse tipo de conselho, aonde se descaracteriza a Política, ocorre uma naturalização de processos sociais mais

\footnotetext{
${ }^{10}$ Trechos disponíveis em < http://www.movimento21dias.com.br/noticia-exibir/hora-rio-de-vera-o-convida-para-a-pratica-de-atividade-fa-sica/3/>. Acesso em 15 de agosto de 2017.
} 
complexos e que requerem soluções do âmbito público. A respeito disso, Alexandre Palma (2009) afirma que ao deixar de lado qualquer contextualização que inclua as novas tecnologias, a violência urbana, a organização do trabalho, entre outros fenômenos, a conotação moral dessas informações pousa sobre o argumento de que os próprios sujeitos seriam os principais responsáveis por um suposto baixo envolvimento com atividades físicas.

Podemos ver também tal conotação moral no momento em que algum argumento científico é transformado em desafio ou em conselho para incentivar e motivar os indivíduos, como se pode perceber em trechos extraídos do site (que também estão presentes no aplicativo) do M21:

A participação em programas de ginástica laboral e adoção de pausas para descansos, dentre outras medidas, são bem-vindas no trabalho e durante o dia. O importante é não ficar parado por longos períodos.

Se for treinar em casa, opte por aplicativos, vídeos e outros meios que ensinam cada movimento. Se escolher uma escola de dança, vá em uma perto de casa ou trabalho para que a distância não seja uma desculpa para você não ir.

Tirar um tempinho para praticar atividades físicas é um importante passo para quem quer correr do sedentarismo e cuidar mais da saúde. E isso só depende de você! Não desista.

Expressões como não desista, só depende de você, desculpa para você não ir, são recorrentes ao largo das plataformas digitais, reforçando toda uma discursividade que joga sobre os sujeitos a responsabilidade pela sua saúde e pelas formas para obter um melhor condicionamento. Por exemplo, de acordo com uma das mensagens extraídas do site, não importa o tipo de trabalho, tampouco o ambiente de serviço ou ainda a relação entre empregado e empregador: segundo o texto do programa o importante é a pessoa realizar qualquer tipo de movimento corporal que se constitua numa atividade física (afinal há muitos locais de trabalho em que não há programas de ginástica laboral, por exemplo). Nota-se, portanto, que esses conselhos não priorizam o espaço público e sim o âmbito (do) privado (GOMES; VAZ; ASSMANN, 2010)

Tais práticas têm demonstrado em sua natureza uma estreita aproximação com a racionalidade neoliberal, agindo sobre os indivíduos de maneira mais distante e menos coerciva, porém sem perder de vista a disciplina, o controle e a normalização da população, valendo-se dos discursos do risco, da economia, do autocuidado e do empreendedorismo de si mesmo (ROSE, 1998; 2011). A racionalidade e as práticas neoliberais que compõem o projeto político predominante nas sociedades contemporâneas têm materialidade nos textos do M21, produzindo, portanto, discursos a partir de enunciados que estão conectados com tal perspectiva. Assim como em outros programas e campanhas ligadas à educação em saúde, o M21 sustenta, a partir de seus conteúdos, as premissas do modelo neoliberal, como a individualização, a responsabilização, a 
diminuição do papel do Estado nas políticas sociais, entre outras (FLEURY, 2017; CASTIEL; MORAES; PAULA, 2016; FURTADO; SZAPIRO, 2016).

Com isso podemos interpretar que a linguagem do M21, embora pretensamente universal e simples, não dialoga com o todo da população que ela pretende alcançar. Tanto os desafios quanto os conselhos acabam por atingir determinados tipos de sujeitos, tal qual outros programas de promoção e educação em saúde já o vem fazendo (LUPTON, 2012; 2000): pessoas de classe média/alta, com renda salarial razoável, inseridos em famílias nucleadas, residentes de zonas urbanas, com acesso a materiais de consumo e serviços e que atuam em trabalhos que requerem menor esforço físico e tempo de deslocamento.

\section{CONSIDERAÇÕES FINAIS}

A partir da leitura e da análise dos conteúdos expostos nas plataformas digitais do M21 a respeito da prática de atividades físicas, entendemos que o programa atua de modo a medicalizar as mesmas, a partir do uso das formações discursivas próprias do campo biomédico, produzindo, entre outras significações, as noções de sedentarismo enquanto patologia e atividade física como remédio. Desse modo o programa em suas plataformas digitais constrói uma narrativa que inscreve no campo médico-sanitário atividades que antes faziam parte do cotidiano das pessoas por motivos mais relacionais que fisiológicos, por exemplo.

Nas plataformas digitais do M21 não são tensionados os motivos que levam à suposta falta de atividade física regular no cotidiano da população. Assim os processos tornam-se naturalizados, individualizados e pautados por soluções pessoais ligadas ao âmbito do privado. Nesse caso os conselhos privados e o processo de medicalização complementam-se no decorrer dos textos, dicas e desafios do programa.

Além disso, as análises dos conteúdos sobre atividade física presentes nos materiais do M21 também nos permitiram pensar o quanto os dispositivos de regulação e controle tem buscado incidir sobre os modos de vida das pessoas a partir do uso das novas tecnologias de saúde móvel. Assim, de acordo com Lupton (2012), os usos dessas tecnologias colocam agentes estatais e privados mais próximos dos sujeitos, podendo assim incrementar um novo rol de estratégias mais sofisticadas de controle, sem, no entanto, necessitarem operar de modo persuasivo e coercivo. Tal tipo de intervenção promovida por esses agentes, que instigam os sujeitos a se responsabilizarem cada vez mais por seus hábitos de vida, emerge em um contexto de crise econômica e da aplicação de medidas de austeridade por parte dos governos, de modo a diminuir/limitar o papel do Estado e consequentemente os investimentos nas políticas sociais. 


\section{REFERÊNCIAS}

ABIB, Leonardo Trápaga. O governo de si e dos outros em dispositivos de saúde móvel: reflexões sobre o "Movimento 21 dias por uma vida mais saudável". Tese (Doutorado em Educação Física) - Centro de Educação Física e Desportos da Universidade Federal do Espírito Santo, Vitória, 2019.

BARRA, Daniela Couto Carvalho et al. Métodos para desenvolvimento de aplicativos móveis em saúde: revisão sistemática da literatura. Texto e Contexto - Enfermagem. Florianópolis, v. 26, n. 4, p. 1-12, 2017.

BAUMAN, Zygmunt. Modernidade líquida. Rio de Janeiro: Zahar, 2001.

BILIBIO, Luiz Fernando; DAMICO, José Geraldo Soares. Carta a um jovem professor. Cadernos de Formação RBCE. Florianópolis, v. 2, n. 2, p. 92-103, 2011.

BONFIM, Mariana Rotta; COSTA, José Luiz Riani; MONTEIRO, Henrique Luiz. Ações de educação física na saúde coletiva brasileira: expectativas versus evidências. Revista Brasileira de Atividade Física e Saúde. Pelotas, v. 17, n. 3, p. 167-173, 2012.

BUSS, Paulo Marchiori. Promoção da saúde e qualidade de vida. Ciência e Saúde Coletiva. Rio de Janeiro-RJ, v. 5, n. 1, p. 163-177, 2000.

BUSS, Paulo Marchiori; CARVALHO, Antônio Ivo de. Desenvolvimento da promoção da saúde no Brasil nos últimos vinte anos (1988-2008). Ciência e Saúde Coletiva. Rio de Janeiro, v. 14, n. 6, p. 2305-2316, 2009.

CALIMAN, Luciana Vieira. Quando os estilos de vida se tornam estilos de risco. In.:

BAGRICHEVSKY, Marcos; ESTEVÃO, Adriana (Orgs.). Saúde Coletiva: dialogando sobre interfaces temáticas. Ilhéus: Editus, 2015, p. 291-318.

CASTIEL, Luis David; MORAES, Danielle Ribeiro de; PAULA, Igor Juliano de.

Terapeuticalização e os dilemas preemptivistas na esfera da saúde pública individualizada. Saúde e Sociedade. São Paulo, v. 25, n. 1, p. 96-107, 2016.

COELHO, Cecília Stahelin; VERDI, Marta Inez Machado. Políticas e programas de atividade física: uma crítica à luz da promoção da saúde. Saúde \& Transformação Social. Florianópolis, v. 6, n. 3, p. 96-108, 2015.

COLLINS, Mike; HAUDENHYUSE, Reinhard. Social Exclusion and Austerity Policies in England: The Role of Sports in a New Area of Social Polarisation and Inequality? Social Inclusion, v. 3, n. 3, p. 5-18, 2015.

CONRAD, Peter. The medicalization of society: on the transformation of human conditions into treatable disorders. Baltimore: The Johns Hopkins University Press, 2007.

DAMICO, José Geraldo Soares. Rasuras disciplinares e amputação de fazeres. Movimento, Porto Alegre, v. 17, n. 3, p. 269-287, 2011. 
DAMICO, José Geraldo Soares; KNUTH, Alan Goulart. O des(encontro) das práticas corporais e atividade física: hibridizações e borramentos no campo da saúde. Movimento, Porto Alegre, v. 20, n.1, p. 329-350, 2014.

DEMAREST, Stefaan et al. Educational inequalities in leisure-time physical activity in 15 European countries. European Journal Public Health, v. 24, n. 2, p. 199-204, 2014.

FERREIRA, Marcos Santos; NAJAR, Alberto Lopes. Programas e campanhas de promoção da atividade física. Ciência e Saúde Coletiva. Rio de Janeiro, v. 10, suppl., p. 207-219, 2005.

FERREIRA, Marcos Santos; CASTIEL, Luis David; CARDOSO, Maria Helena Cabral de Almeida. Atividade física na perspectiva da Nova Promoção da Saúde: contradições de um programa institucional. Ciência \& Saúde Coletiva. Rio de Janeiro, v. 16, n. 1, p. 865-872, 2011.

FLEURY, Sonia. Welfare State in Latin America: reforms, innovations and exhaustion. Cadernos de Saúde Pública. Rio de Janeiro, v. 33, suppl 2, 2017. Disponível em http://www.scielo.br/scielo.php?script=sci_arttext\&pid=S0102-

311X2017001400501\&lng=en\&nrm=iso . Acesso em 10 de maio de 2019.

FOUCAULT, Michel. Crise da medicina ou da anti-medicina. Verve. São Paulo, v. 18, p. 167-194, 2010.

FRAGA, Alex Branco. Exercício da informação: governo dos corpos no mercado da vida ativa. Campinas: Autores Associados, 2006.

FRAGA, Alex Branco et al. "Sedentarismo é...": concepções de praticantes de caminhada e medicalização das práticas corporais. In: FRAGA, Alex Branco; MAZO, Janice Zarpellon; STIGGER, Marco Paulo (Orgs.). Políticas de lazer e saúde em espaços urbanos. Porto Alegre: Gênese, 2015, p. 21-35.

FURTADO, Mariama Augusto; SZAPIRO, Ana Maria. Política Nacional de Promoção da Saúde: os dilemas da autonomização. Saúde e Sociedade. São Paulo, v. 25, n. 2, p. 277-289, 2016.

GASTALDO, Denise. É a educação em saúde “saudável”? Repensando a Educação em Saúde através do conceito de bio-poder. Educação e Realidade. Porto Alegre, v. 22, n. 1, p. 147-168, 1997.

GAUDENZI, Paula; ORTEGA, Francisco. O estatuto de medicalização e as interpretações de Ivan Illich e Michel Foucault como ferramentas conceituais para o estudo da desmedicalização. Interface. Botucatu, v. 16, n. 40, p. 21-34, 2012.

GOMES, Ivan Marcelo. Conselheiros Modernos: propostas para a educação do indivíduo saudável. Tese (Doutorado Interdisciplinar em Ciências Humanas) - Centro de Filosofia e Ciências Humanas da Universidade Federal de Santa Catarina, Florianópolis, 2008.

GOMES, Ivan Marcelo; VAZ, Alexandre Fernandez; ASSMANN, Selvino. Conselheiros midiáticos: o "Caderno Equilíbrio" da Folha de São Paulo e suas ponderações na formação do indivíduo saudável. Movimento, Porto Alegre, v. 16, n. 4, p. 117-134, 2010. 
HOLTERMANN, Andreas et al. The health paradox of occupational and leisure-time physical activity. British Journal of Sports Medicine, v. 46, n. 4, p. 291-295, 2012.

LUPTON, Deborah. Corpos, prazeres e práticas do eu. Educação e Realidade. Porto Alegre, v. 25, n. 2, p. 45-58, 2000.

LUPTON, Deborah. M-health and health promotion: The digital cyborg and surveillance society. Social theory e health, v. 10, n. 3, p. 229-244, 2012.

MANSKE, George Saliba; BARCELOS, Thaís Silveira. Práticas corporais medicalizantes: diagnosticando a Revista Vida Simples. Movimento. Porto Alegre, v. 22, n. 1, p. 233-246, 2016.

Matravolgyi, Júlia. Plataformas para saúde já têm 165 mil aplicativos. Valor Econômico, 21 de nov. de 2016. Disponível em

http://www.i9access.com.br/noticias_arquivos/valor_plataformas_2016.pdf. Acessado em $30 \mathrm{de}$ novembro de 2018

NETO, João Leite Ferreira et al. Apontamentos sobre Promoção da Saúde e biopoder. Saúde e Sociedade. São Paulo, v. 18, n. 3, p. 456-466, 2009.

PALMA, Alexandre et al. Os "pesos" de ser obeso: traços fascistas no ideário de saúde contemporâneo. Movimento. Porto Alegre, v. 18, n. 4, p. 99-119, 2012.

PALMA, Alexandre. Exercício físico e saúde; sedentarismo e doença: epidemia, causalidade e moralidade. Motriz, Rio Claro, v. 15, n. 1, p. 185-191, 2009.

PICH, Santiago. Saberes do/sobre o corpo: governamentalidade, biopolítica e cuidado de si. In: CARVALHO, Yara Maria; FRAGA, Alex Branco; GOMES, Ivan Marcelo (Orgs.). As práticas corporais no campo da saúde. São Paulo: Hucitec, 2016, p. 154-171.

PICH, Santiago; GOMES, Ivan Marcelo; VAZ, Alexandre Fernandez. Mercadorização biopolítica: sobre escolhas saudáveis em tempos de consumo. In.: BAGRICHEVSKY, Marcos; ESTEVÃO, Adriana; PALMA, Alexandre (Orgs.). A saúde em debate na Educação Física - Volume 3. Ilhéus: Editus, 2007, p. 187-208.

REIS, Rodrigo et al. Scaling up physical activity interventions worldwide: stepping up to larger and smarter approaches to get people moving. The Lancet, v. 388, n. 10051, p. 1337-1348, set. 2016.

ROCHA, Thiago Augusto Hernandes et al. Saúde Móvel: novas perspectivas para a oferta de serviços em saúde. Epidemiologia e Serviços de Saúde. Brasília, v. 25, n. 1, p. 159-170, 2016.

RODRIGUES, Phillipe et al. Prática de atividade física no lazer e condições socioeconômicas no município do Rio de Janeiro. Revista saúde física e mental. Nova Iguaçu, v. 5, n. 2, p. 18-30, 2017.

ROSE, Nikolas. Governando a alma: a formação do eu privado. In.: SILVA, Tomaz Tadeu (Org.). Liberdades reguladas. A pedagogia construtivista e outras formas de governo do eu. Petrópolis: Vozes, 1998, p. 30-45. 
ROSE, Nikolas. Inventando nossos Selfs: Psicologia, Poder e Subjetividade. Petrópolis: Ed. Vozes, 2011.

SALLIS, James et al. Physical activity in relation to urban environments in 14 cities worldwide: a cross-sectional study. The Lancet, v. 387, p. 2207-2217, 2016.

STRINGHINI, Silvia et al. Socioeconomic status and the $25 \times 25$ risk factors as determinants of premature mortality: a multicohort study and meta-analysis of 1.7 million men and women. The Lancet, v. 389, p. 1229-1237, 2017.

VAZ, Alexandre Fernandez. Da polifonia do corpo à multiplicidade de sua educação. Perspectiva Revista do Centro de Ciências da Educação. Florianópolis, v. 21, n. 1, p. 7-11, 2003.

VERDI, Marta; CAPONI, Sandra. Reflexões sobre a promoção da saúde numa perspectiva bioética. Texto contexto - enfermagem. Florianópolis, v. 14, n. 1, p. 82-88, 2005.

WHO. mHealth: New horizons for health through mobile technologies: second global survey on eHealth. Disponível em: http://www.who.int/goe/publications/goe mhealth web.pdf Acessado em 26 de abril de 2018.

\section{NOTAS DE AUTOR}

\section{AGRADECIMENTOS}

Não se aplica.

\section{CONTRIBUIÇÃO DE AUTORIA}

Não se aplica

\section{FINANCIAMENTO}

Coordenação de Aperfeiçoamento de Pessoal de Nível Superior (Capes).

\section{CONSENTIMENTO DE USO DE IMAGEM}

Não se aplica.

\section{APROVAÇÃO DE COMITÊ DE ÉTICA EM PESQUISA}

Aprovado pelo Comitê de Ética e Pesquisa da Universidade Federal do Espírito Santo, número de parecer 2.264.111

\section{CONFLITO DE INTERESSES}

Não se aplica.

\section{LICENÇA DE USO}

Os autores cedem à Motrivivência - ISSN 2175-8042 os direitos exclusivos de primeira publicação, com o trabalho simultaneamente licenciado sob a Licença Creative Commons Attribution Non-Comercial ShareAlike (CC BY-NC SA) 4.0 International. Esta licença permite que terceiros remixem, adaptem e criem a partir do trabalho publicado, desde que para fins não 
comerciais, atribuindo o devido crédito de autoria e publicação inicial neste periódico desde que adotem a mesma licença, compartilhar igual. Os autores têm autorização para assumir contratos adicionais separadamente, para distribuição não exclusiva da versão do trabalho publicada neste periódico (ex.: publicar em repositório institucional, em site pessoal, publicar uma tradução, ou como capítulo de livro), com reconhecimento de autoria e publicação inicial neste periódico, desde que para fins não comerciais e compartilhar com a mesma licença.

\section{PUBLISHER}

Universidade Federal de Santa Catarina. Programa de Pós-Graduação em Educação Física. LaboMídia - Laboratório e Observatório da Mídia Esportiva. Publicado no Portal de Periódicos UFSC. As ideias expressadas neste artigo são de responsabilidade de seus autores, não representando, necessariamente, a opinião dos editores ou da universidade.

\section{EDITORES}

Mauricio Roberto da Silva, Giovani De Lorenzi Pires, Rogério Santos Pereira

\section{HISTÓRICO}

Recebido em: 22 de maio de 2019.

Aprovado em: 20 de abril de 2020. 